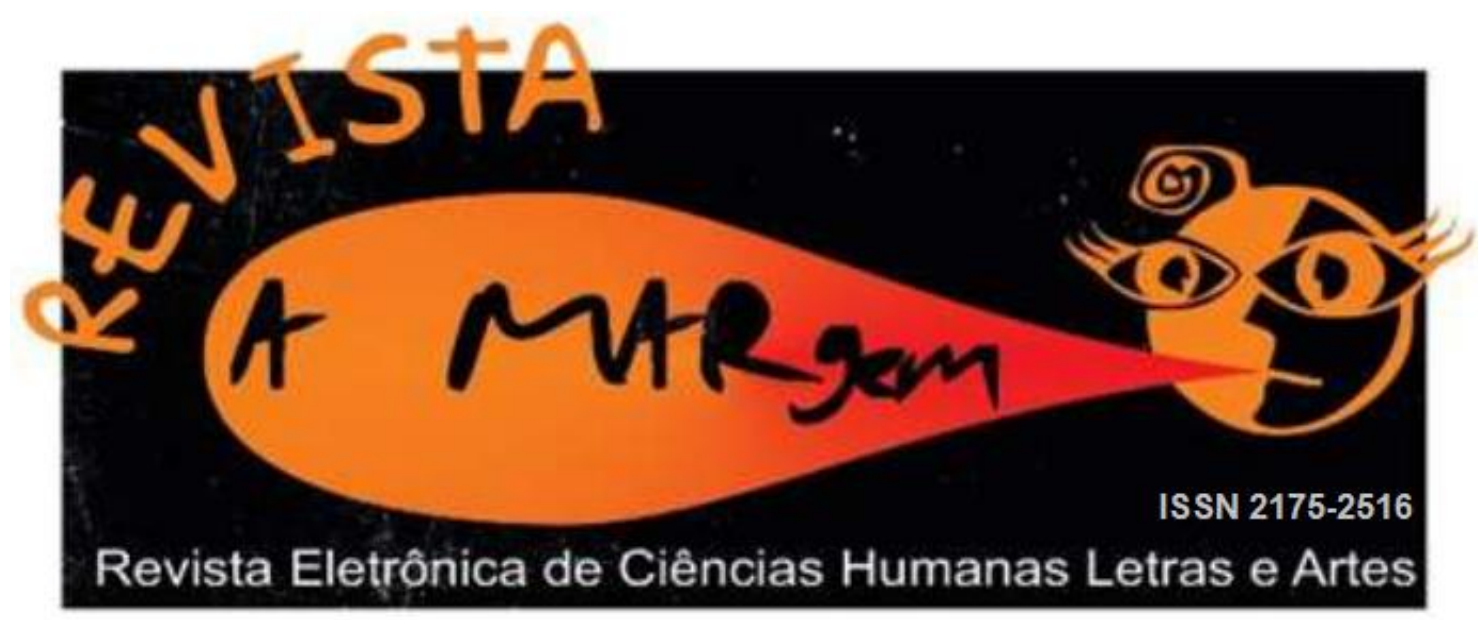

\title{
MOVIMENTOS TRANSNACIONAIS E CONSTRUÇÕES IDENTITÁRIAS: UMA ANÁLISE DA IMPERMANÊNCIA E DA FLUIDEZ NA NARRATIVA DE ADRIANA LISBOA
}

\section{Fábio Santana ${ }^{1}$ Universidade Federal de Catalão (UFCat) \\ Cimara Valim de Melo Instituto Federal de Educação, Ciência e Tecnologia (IFRS)}

Resumo: A contemporaneidade trouxe consigo a (des/re)construção da noção de identidade, a qual passa da fixidez à fluidez. A partir dessa premissa, o presente artigo visa à análise do processo de construção identitária individual e coletiva a partir da representação literária, tomando como base o conto "O escritor, sua mulher e o gato", presente no livro O sucesso (2016), de Adriana Lisboa. Busca-se, assim, compreender como a narrativa brasileira contemporânea, tomando como exemplo o conto, tem representado o indivíduo em termos identitários por meio dos trânsitos realizados pelas personagens. Os estudos de Zygmunt Bauman (1996, 2005, 2012) e Stuart Hall (1996, 2005) sobre identidade, mobilidade e globalização servem como referencial do trabalho, cuja análise parte da fluidez identitária do protagonista em sua relação com elementos simbólicos presentes no texto. Como resultado, observa-se que há uma tendência na narrativa brasileira contemporânea em representar indivíduos fluídos, desenraizados de seus espaços de origem, os quais experimentam a mobilidade sob diferentes perspectivas, trazendo consigo as consequências da globalização em termos culturais.

Palavras-chave: Literatura contemporânea. Adriana Lisboa. Identidade.

\footnotetext{
${ }^{1}$ Graduando em Letras Português/Inglês na Unidade Acadêmica Especial de Letras e Linguística da Universidade Federal de Catalão. Contato: fabio.freitasantana@gmail.com

${ }^{2}$ Professora da área de Letras do Instituto Federal de Educação, Ciência e Tecnologia do Rio Grande do Sul (IFRS), com Pós-Doutorado em Estudos Brasileiros pelo King's Brazil Institute (King's College London) e Doutorado em Estudos de Literatura pela Universidade Federal do Rio Grande do Sul (UFRGS). Coautora deste trabalho. Contato: cimara.valim@gmail.com
} 


\title{
TRASNATIONAL MOVEMENTS AND IDENTITY BUILDING: AN ANALYSIS OF IMPERMANENCE AND FLUIDITY IN ADRIANA LISBOA'S NARRATIVE
}

\begin{abstract}
Contemporaneity has brought with it the (de/re)construction of the notion of identity, which passes from fixity to fluidity. From this premise, the present article aims at the analysis of the process of individual and collective identity building from literary representation, by having as a basis the short story "O escritor, sua mulher e o gato" from the book $O$ sucesso (2006) by Adriana Lisboa. We seek to investigate how contemporary Brazilian narrative, especially short story, has represented the individual in terms of identity through movements performed by characters. Studies taken by Zygmunt Bauman (1996, 2005, 2012) and Stuart Hall $(1996,2005)$ on identity, mobility and globalization provide a theoretical framework for this essay, which analyzes the protagonist's fluid identity in relation to symbolic elements present in the narrative. As a result, we observe a tendency of contemporary Brazilian narrative to represent fluid characters, uprooted from their original spaces, who experiment mobility through different perspectives, bringing together globalization's cultural consequences.
\end{abstract}

Keywords: Contemporary literature; Adriana Lisboa; Identity.

\section{INTRODUÇÃO}

A literatura brasileira das últimas décadas, influenciada em grande parte pelos reflexos da globalização em nível cultural ${ }^{3}$, tem representado em seus textos a pluralidade de elementos que constituem o sujeito contemporâneo. Um "mundo de povos e culturas plurais", como alerta Homi Bhabha (1994, p. xiv), cujas margens fazem-se cada vez mais difusas, passa por indivíduos migrantes dos mais diversos contextos - políticos, econômicos, sociais, culturais pelos quais se dissolve a dicotomia local x global. Nesse contexto, Zygmunt Bauman (2012, p.2) destaca que, em um tempo de "compressão do tempo/espaço", a condição humana precisa cada vez mais lidar com elementos como a hibridização cultural, o estranhamento e a sensação permanente de movimento. É nos meandros de seres on the move, pertencentes a um mundo em constante transformação, que o processo de globalização toma forma, expondo como parte de si a "segregação", a "separação" e a "exclusão" (BAUMAN, 2012, p. 3).

Frente ao exposto, a narrativa no século XXI traz à tona questões individuais que permeiam seres deslocados, representativos da dissolução das fronteiras entre local e global. "Não há mais espaço para o coletivo, uma vez que não se pode mais considerar que os sujeitos

\footnotetext{
${ }^{3}$ A globalização cultural é definida por James Watson (2017) como um fenômeno pelo qual a experiência do cotidiano, influenciada pela difusão de comodities e ideias, reflete a estandardização de expressões culturais pelo mundo, em muito impulsionada pela comunicação digital, pelo comércio virtual, pela cultura pop e pelas viagens internacionais.
} 
dessas narrativas sejam uma massa única e condensada" (MÜLLER, 2011, p.1), mas sim a junção de diversos elementos que se sobrepõem a sua história. O foco narrativo está justamente nesse sujeito fragmentado a buscar, ao seu redor, componentes que corroborem a sua identidade. Cabe ressaltar que, além do rompimento com a composição identitária de seus personagens, há a quebra de tabus, pois a literatura contemporânea ${ }^{4}$ contempla

escritores não vinculados a grandes editoras e representantes de vozes pouco presentes no cotidiano da literatura brasileira canônica ou bastante difundida (como autores e autoras negros, escritores indígenas ou provenientes de contextos marginalizados socialmente, como os dos grupos LGBT e da periferia, entre outros) (PORTO, L.; PORTO, A., 2018, p.1).

Ao entendermos o contexto no qual a literatura atual está inserida, partimos para a eleição do gênero a ser estudado, chegando ao conto como corpus do presente estudo, visto a sua mobilidade e Esse gênero textual ganhou forças com Edgar Allan Poe, primeiro contista a teorizar sobre a categoria, e Julio Cortázar, principal teórico do conto. Ambos destacaram a sua fluidez e ruptura em relação a outros gêneros literários, como o romance por exemplo. Para Edgar Allan Poe (1997), aquele deveria ser lido em pouco tempo, com uma estrutura breve, mas não necessariamente objetiva, que levasse o leitor à exaltação da alma.

Assim sendo, observamos que o conto contemporâneo bem representa o sujeito individual: "sendo um conjunto de sincronias, ele assoalha a estrutura para que surjam as diversas facetas do homem contemporâneo. Ele não representa o ser como se este fosse completo, mas sim de acordo com as várias representações" (MÜLLER, 2011, p.2). Por isso, a escolha do gênero neste estudo a partir da perspectiva identitária, já que, em sua essência, aquele está imerso em uma hibridez de cores e sentidos, partindo da sua própria "limitação" dentro do tempo-espaço da narrativa.

O presente artigo pretende, assim, refletir sobre a noção de (não)pertencimento por meio da análise do conto "O escritor, sua mulher e o gato", presente na obra O sucesso (2016), de Adriana Lisboa. O estudo centra-se na relação entre narrador, personagens e fluidez identitária,

\footnotetext{
${ }^{4}$ Os limites que circundam o termo 'literatura contemporânea' são difusos, o que torna problemática qualquer tentativa de recorte temporal para o termo. Contudo, é interessante trazer aqui a discussão levantada por Karl Erik Schøllhammer (2009, p. 9-10) acerca do contemporâneo, segundo o qual, e a partir da aproximação de Barthes sobre o contemporâneo e o intempestivo, o termo nos remete ao que é capaz de captar o seu tempo e enxergá-lo; "assim, a literatura contemporânea não será necessariamente aquela que representa a atualidade, a não ser por uma inadequação, uma estranheza histórica que a faz perceber as zonas marginais e obscuras do presente [...]". Isso porque o contemporâneo é "capaz de se orientar no escuro", de "reconhecer e de se comprometer com um presente com o qual não é possível coincidir.”
} 
bem como no elo que se estabelece entre espaços reais e simbólicos estabelecidos na confluência entre diferentes identidades e subjetividades.

Logo, artigo analisa questões pertinentes à conciliação entre a identidade do fotógrafo e os elementos simbólicos presentes no texto, tendo como base os pressupostos de Cortázar (1973), Poe (1997) e Piglia (1994) acerca do conto, bem como os estudos de Bauman (1996, 2005, 2012) e Hall (1996, 2005) sobre globalização e identidade. O trabalho está dividido em três seções: primeiramente, discutimos a questão da identidade em termos teórico-críticos, buscando a sua relação com o gênero conto; a seguir, apresentamos a análise do conto "O escritor, sua mulher e o gato", de Adriana Lisboa; por fim, analisamos a simbologia presente no conto analisado, bem como sua contribuição à representação das reconfigurações identitárias pelo tempo-espaço contemporâneo.

\section{A identidade como 'ser peregrino'}

A literatura brasileira do século XXI traz consigo a problematização do conceito de identidade, uma vez que esta se reconstrói face aos reflexos da globalização. Nesse sentido, Bauman (2005, p. 35) afirma que "em nossa época líquido-moderna, em que o indivíduo livremente flutuante, desimpedido, é o herói popular"; a identidade, vista como uma "rede de conexões", promove a dissolução da polaridade local x global, produzindo, a partir dessa transformação, novas identidades, cada vez mais fluidas e mutáveis. A produção literária atual busca, com isso, representar identidades diversas, pautadas pela hibridez de povos e culturas, o que acaba por trazer à tona 'cidadãos do mundo', sempre em movimento, que buscam construir o seu 'eu' a partir dos subsídios fornecidos pelo espaço ao qual estão alocados. Nesse sentido, "pensar o sistema literário do século XXI é deparar-se com uma complexidade cada vez maior de trânsitos vividos e representados por autores e obras, os quais estão direta ou indiretamente imbricados às transformações trazidas à contemporaneidade pela globalização" (MELO, 2017, p.13).

Fixidez e enraizamento dão lugar a mobilidade e errância em um mundo marcado pelos reflexos da globalização cultural, pela qual novos processos de (des/re) territorialização auxiliam na redefinição do indivíduo. Tais questões contribuem à crise identitária já observada por Bauman (1996, p.18). Para ele,

se o 'problema de identidade' do moderno foi como construir uma identidade e mantê-la sólida e estável, o 'problema de identidade' do pós-moderno é 
primeiramente como evitar fixação e manter as opções abertas. No caso de identidade, como em outros casos, a palavra-chave da modernidade era criação; a palavra-chave da pós-modernidade é reciclar. (tradução nossa)

Bauman (1996, p.19, tradução nossa) sustenta que "a modernidade construiu sua estrutura preocupada com a durabilidade de seu período; de outro modo, a pós-modernidade constrói sua estrutura diariamente em plástico biodegradável", sem se preocupar com a durabilidade, pois se vive em uma era de intensa globalização e de mudanças constantes - o que hoje é verdade, amanhã pode não ser. Há um grande leque de oportunidades, conforme afirma o sociólogo: "uma pessoa não tem certeza de como se colocar perante a evidente variedade de estilos e padrões comportamentais".

Imagens como as do andarilho, do vagabundo e do turista permeiam o desenraizamento e a fluidez provenientes da contemporaneidade. Tais categorias, conforme Bauman (1996), permitem compreendermos como a crise identitária está diacronicamente associada à história humana. Inicialmente percorrendo a imagem do peregrino, Bauman (1996, p.20; tradução nossa) propõe que a verdade deste está em outro lugar: o seu local de (re)encontro está distante; ele está sempre em movimento, insatisfeito, questionando inclusive qual o propósito da cidade em sua jornada: "Somente as ruas fazem sentido, não as casas - casas servem para descansar. Mesmo as ruas podem ser mais obstáculos do que ajuda".

Para o sociólogo (BAUMAN, 1996), a principal diferença entre o vagabundo, o turista e o andarilho é que, enquanto o primeiro se acomoda em qualquer lugar que lhe pareça confortável, o segundo se submete a experiências diversas em busca de uma aproximação com outras culturas, a fim de pertencer ao grupo no qual está visitando, mesmo que seja por pouco tempo. $\mathrm{O}$ andarilho, por outro lado, busca construir sua história pela não identificação, como se caminhasse no deserto e, ao olhar para trás e encontrar suas pegadas, pudesse observá-las como locais pelos quais já passou e que contribuíram para sua formação. Ao mesmo tempo, olha para frente, mirando o incerto, mas na busca de encontrar algo que o completará.

Poderíamos experimentar uma analogia entre a projeção identitária desenvolvida por Bauman (1996) e o gênero literário escolhido para o presente estudo - o conto -, uma vez que este também experimenta a crise identitária. Percebemos o esforço de diversos autores na busca de uma definição para essa forma literária, a exemplo de Poe (1997), para o qual o gênero deveria ser lido entre meia e duas horas. Além disso, ele defende a ideia de que

o escritor de contos em prosa pode incorporar ao seu tema uma variadíssima série de modos ou inflexões do pensamento e da expressão, [...] antagônicos a 
natureza do poema e vedados por um dos mais peculiares e indispensáveis elementos: o ritmo. (POE, 1997, p. 304)

Outro teórico do conto, Julio Cortázar (1974), relaciona narrativa curta e longa, uma vez que, para ele, o conto trabalha na sua limitação, por não ter a extensão de um romance. O conto é "uma síntese viva ao mesmo tempo em que uma vida sintetizada, algo assim como um tremor de água dentro de um cristal, uma fugacidade numa permanência"; é, contudo, difícil de ser demarcado, esvaindo-se através do tempo-espaço, pelo qual forma uma unidade.

As peculiaridades estruturais do conto - entre elas, a brevidade e a condensação narrativa -, aliadas a sua fluidez e flexibilidade na contemporaneidade, fazem-no espaço narrativo privilegiado para a problematização de questões atreladas às noções de identidade, alteridade e pertencimento. Isso porque o conto contemporâneo quebra com estruturas tradicionais de análise da narrativa curta, trazendo consigo subversão e marginalidade, o que o coloca em uma posição de fronteira e redefinição identitária. Tal posição nos remete ao 'entrelugar' percebido por Silviano Santiago (2000, p. 16) na literatura latino-americana: “A maior contribuição da América Latina para a cultura ocidental vem da destruição sistemática dos conceitos de unidade e de pureza", visto o seu movimento de "desvio da norma", que a coloca ao mesmo tempo em uma posição de busca e (re)encontro de sua própria condição em meio à hibridez e ao deslocamento. Dentro desse contexto, o conto brasileiro contemporâneo colabora à reconfiguração do conceito de 'fronteira', conferindo espaço ao que Stuart Hall (2005, p. 8) intitula "identidades culturais", ou seja, aspectos identitários atrelados à noção de pertencimento a "culturas étnicas, raciais, linguísticas, religiosas e, acima de tudo, nacionais" - questões claramente presentes na contística de Adriana Lisboa.

\section{O fotógrafo: analisando a 'fuga das sombras' na cidade-luz}

O conto "O escritor, sua mulher e o gato", presente no livro O sucesso (2016), de Adriana Lisboa, vai ao encontro da problematização identitária pelo viés do deslocamento. Composto por nove narrativas, a obra apresenta diversas histórias que nos remetem ao questionamento da condição subjetiva frente à falta de fixidez experimentada em tempos globais. Nesse sentido, Hall (2005, p. 71) menciona que a identidade está diretamente envolvida no processo de representação: "a moldagem e a remoldagem de relações espaço-tempo no interior de diferentes sistemas de representação têm efeitos profundos sobre a forma como as identidades são localizadas e representadas.” Assim, o espaço de representação literária traduz- 
se, na contemporaneidade, como veículo de expressão de indivíduos que, em muito, constituem-se como seres peregrinos, marcados pela errância e pela instabilidade identitária.

A experiência da mobilidade e do desenraizamento é retratada em "O escritor, sua mulher e o gato", história de um fotógrafo contratado para fotografar um escritor francês, judeu de origem alemã, que vivia em Paris com sua esposa Lucie. Entretanto, uma situação o deixa sem rumo: o duplo suicídio do escritor e de sua mulher. A partir daí, ele vive uma busca desenfreada por sentido, movimento que corrobora a condição do narrador-viajante enquanto ser fragmentado, desenraizado, cujas relações apresentam-se esfaceladas, fazendo com que não se sinta parte de lugar algum.

Em relação ao gênero conto, observamos que o movimento realizado pela personagem, em especial após saber da morte do casal, pode ser compreendido pela duplicidade narrativa, ou melhor, a configuração do texto pelas dimensões visível e invisível, que perfazem o conto pelo recurso de uma história dentro da outra e, consequentemente, conferem-lhe uma identidade complexa, dúbia. Conforme Ricardo Piglia (1994) um conto sempre narra duas histórias: uma história dada pela escrita e outra oculta, que produz surpresa pelo não dito - histórias que, no conto contemporâneo, surgem como se fossem apenas uma história. No texto em questão, a história escrita, que nos é apresentada, narra a ida do fotógrafo a Paris, a fim de fotografar um autor esquecido do grande público; já a história oculta, vista por meio do simbolismo da fotografia, é a que traz consigo a impermanência do protagonista em meio a seus trânsitos geográficos. Cabe acrescentar que as duas histórias ocorrem concomitantemente, tramando-se de modo a formar um todo que pode ser visto sob diferentes primas.

Ao iniciar o texto com a frase "Fazer a mala", Adriana Lisboa já nos dá pistas do que vai acontecer: uma viagem. Não uma simples viagem a passeio, mas a trabalho. Entretanto, a personagem - "o fotógrafo" - não parece totalmente animada com a ideia. É esse o nosso ponto de partida para a análise. Por que não estar animado com a ideia de ir para Paris, a cidade-luz? A partir do fato de que ele precisa comprar uma mala, pois a antiga havia ficado com ex-mulher, "assim como o filho, o cachorro, as panelas, a roupa de cama e todo o resto" (LISBOA, 2016, p.113), percebemos a existência frágil da personagem enquanto sujeito representado. Durante catorze anos, foi dependente da mulher para tudo. A partir do momento em que não há mais ninguém, ele se sente perdido, pois nem o filho está com ele, colocando-se indiretamente num "limbo identitário": nem é nem deixa de ser, apenas existe. Isso pode ser observado inclusive na narrativa, pois, segundo afirma Teixeira (2017, p. 69), a mesma "é conduzida pelo narrador- 
protagonista, que oscila em seu discurso, ou seja, a narração é elaborada ora por uma voz em terceira pessoa, que refere a 'si mesmo' como 'outro', ora por uma voz em primeira pessoa", pela qual a subjetividade toma forma.

A história do protagonista começa a mudar a partir de seu contato com o escritor Gérard Baer, motivo de sua viagem a Paris. Apesar de não estar totalmente entusiasmado com a ida, entende, em seu interior, que ali está uma oportunidade de se (re)encontrar: "abrir os olhos e se deparar com algo muito diferente de" si (LISBOA, 2016, p. 115). Após comprar as passagens e pagar a hospedagem por sua conta - não iria receber o suficiente para cobrir os gastos -, o protagonista embarca para Paris, a fim de cumprir com o seu trabalho. Apesar de o deslocamento aparente ser geográfico (Brasil-França), observamos também que o narrador se configura internamente como um deslocado, porque, ao chegar ao seu destino, ele não é mais o pai, o ex-marido: é tão somente o fotógrafo, como se tivesse deixado praticamente tudo para trás. Nesse sentido, ele mesmo questiona, ao se dirigir ao apartamento, sobre a quem as cidades pertenciam. "Aos que nasceram e cresceram ali? Aos imigrantes, refugiados, estrangeiros? Será que aquela cidade tinha, lá no seu íntimo, seus favoritos? Será que tinha seus eleitos?". (LISBOA, 2016, p.120)

A cidade, na narrativa brasileira contemporânea, tem papel fundamental, visto que delimita o espaço físico no qual a obra se passa e, mais do que isso, exerce influência sobre o tempo-espaço da narrativa. É o refúgio daqueles que querem escapar de algum lugar e buscam, no aglomerado da urbe, uma nova chance. É por sua paradoxal condição, a abarcar ausência e presença, que o indivíduo - estrangeiro solitário - se protege na multidão. Entretanto, não é para todos que a cidade se mostra acolhedora: ela só 'pertence' àqueles que se dispõem a explorá-la, a esmiuçar todos os seus cantos em busca de abrigo. E quem mais se dispõe a investigar um lugar? Um viajante, aquele que está só de passagem. Nesse sentido, Bauman (2005, p. 32-33) destaca que "nós, os habitantes do líquido mundo moderno" construímos identidades em movimento, pois o vagar pela cidade é justamente a representação da busca pela identidade individual e coletiva - "no admirável mundo novo das oportunidades fugazes e das seguranças frágeis, as identidades ao estilo antigo, rígidas e inegociáveis, simplesmente não funcionam".

Dentre as situações vividas que confrontam o protagonista com o transitório e repercutem em sua constituição identitária, destacamos a que o aproxima do casal francês. Inicialmente, ele vai jantar na casa de Baer e Lucie. Têm uma noite agradável de conversa, 
tiram algumas fotos no apartamento do casal e pelas ruas parisienses. Dialogam sobre a vida do escritor, que é francês, mas guarda consigo a identidade de judeu de origem alemã. Menos de vinte e quatro horas depois, o fotógrafo descobre que Gérard e Lucie cometeram suicídio. A mulher já vinha com uma doença em estágio avançado, e o escritor, sem conseguir imaginar sua vida sem ela, resolve dar fim a sua própria, junto da esposa. Após a notícia recebida, o protagonista sai sem rumo, fotografando tudo o que vê, até que entra em uma loja de brinquedos para se proteger da chuva e da dor da perda: "ali dentro eu estava ao abrigo da chuva fina e do frio discreto e da vida inteira, quem me dera poder não ir mais embora, quem me dera tornarme uma espécie de câmera contínua da loja de brinquedos." (LISBOA, 2016, p.142)

Ao final da narrativa, o narrador-personagem encontra-se nos braços de Carla, uma 'exfutura' atriz, brasileira filha de francês, braços estes que ele buscava incessantemente, mesmo sem saber. $O$ final do conto torna-se, assim, o começo da sua história, pois a personagem parece encontrar algum sentido, alguma direção para si mesma: "talvez não fosse preciso, no fim das contas, seguir em frente. Talvez fosse possível apenas ficar ali, parado, naquele abraço" (LISBOA, 2016, p. 147).

Notamos, a partir da leitura, que os deslocamentos enfrentados pelas personagens no conto de Lisboa vão muito além da simples travessia geográfica, uma vez que envolvem uma série de questões individuais. Devemos nos atentar que "transitar de um espaço ao outro, distanciar-se do lugar que propicia segurança é sempre uma experiência que desencadeia rupturas, pois quem se entrega à travessia permanece situado entre um estranho sentimento de nostalgia e privação" (TEIXEIRA, 2017, p. 70). Para além da realização de um simples trabalho, o narrador-personagem busca, em sua ida à França, fugir da sua zona de conforto para encarar um país com uma língua estranha, conviver com pessoas desconhecidas, perder-se entre as ruas de uma cidade feita de luzes e sombras - tal como é a matéria fotográfica. É justamente por meio de elementos não conhecidos que ele se situa, tendo em vista que, ao sair de sua terra natal e partir para outro lugar, se vê na posição de estrangeiro, de errante em território igualmente estrangeiro. Surge, portanto, a necessidade de se reinventar, de buscar algo que faça com que se sinta parte de um todo, "pois o deslocamento desencadeia um desconfortável sentimento de estar fora, ocupando um lugar que não lhe pertence” (TEIXEIRA, 2017, p. 72). 


\section{O simbolismo ${ }^{5}$ como elemento identitário}

Adriana Lisboa é conhecida por se valer dos movimentos transnacionais na construção de suas obras, mas ela vai além. Podemos dizer que o simbolismo também caracteriza os seus textos, os quais são carregados de elementos que contribuem à complexa relação entre sujeito e imaginário. Como exemplo, temos o romance Rakushisha (2007), no qual a autora traz, durante toda a história, referências ao mestre de haicais, Matsuo Bashô, relacionando os deslocamentos da protagonista Celina aos passos do poeta e à imagem dos 'caquis caídos'. Também os romances Azul-corvo (2010) e Hanói (2013) são ricos na exploração de elementos simbolicamente constituídos, ou seja, que possuem forte valor nas relações que travam entre literatura, mito e imaginário, a exemplo do mar e da música, respectivamente, os quais possuem um conjunto de signos e representações a eles vinculados.

No conto "O escritor, sua mulher e o gato" não é diferente, uma vez que a autora utiliza uma série de elementos simbólicos no decorrer da narrativa. Inicialmente temos o jogo de luzes e sombras que permeia o texto. A viagem para Paris representa tal ideia, visto que, apesar de a viagem ocorrer no verão, época na qual o sol não se põe antes das 21 horas e o clima é agradável, não é essa a sensação que se vê no conto. A cidade-luz é melancólica, triste, cinza. O clima é um elemento que externa os sentimentos do protagonista: sempre que algo de importante está para acontecer, o tempo fecha e começa a chover. Um exemplo está na relação que a narrativa estabelece entre a dor sentida pelo fotógrafo ao relembrar a morte do escritor e as ruas chuvosas de Paris, por onde aquele se desloca até entrar em uma loja de brinquedos: "ali dentro eu estava ao abrigo da chuva e do frio discreto e da vida inteira, quem me dera poder não ir mais embora" (LISBOA, 2016, p.141-142). A exploração dos processos climáticos representa até o sentimento do protagonista por Carla: "pela primeira vez desde que eu tinha chegado à cidade o céu se abria pra valer e o sol afirmava que era, de fato, verão" (LISBOA, 2016, p.146). Essa

\footnotetext{
${ }^{5} \mathrm{O}$ termo aqui utilizado remete ao imaginário existente entre os signos e o sujeito, os quais estão, conforme Chevalier e Gheerbrant (2009, p. xi-xii), unidos pelo valor simbólico, seus sentidos ocultos e suas realidades circundantes: "Os símbolos estão no centro, constituem o cerne dessa vida imaginativa. Revelam os segredos do inconsciente, conduzem às mais recônditas molas da ação, abrem o espírito para o desconhecido e o infinito. [...] A expressão simbólica traduz o esforço do homem para decifrar a subjugar um destino que lhe escapa através das obscuridades que o rodeiam." O simbolismo está no centro das relações entre literatura, mito e imaginário e remete à Antiguidade, em especial a Platão e a Aristóteles. No século XX, passa pelos estudos de Carl Gustav Jung - o qual produz uma importante teoria do simbolismo, que serve de base para diversas outras -, Ernst Cassirer, Gaston Bachelard e Gilbert Durand, entre outros.
} 
passagem se dá quando ele vai ao encontro dela, além de representar sua rendição a uma vida nova, à ideia de se (re)construir em um novo lugar.

Outra dualidade simbólica percebida no conto de Lisboa é a existente entre fluidez e permanência. Gerard, apesar de ser francês judeu e de origem alemã, não apresenta características comuns de um ser movente, híbrido. Morava há mais de três décadas no mesmo apartamento, há oitenta e cinco na mesma cidade e era casado com uma única pessoa por cinquenta e seis anos. Sempre usava as coisas "até elas quebrarem ou estragarem e ser preciso jogar fora" (LISBOA, 2016, p.131). Todos esses aspectos geram um paradoxo com o indivíduo problemático representado pela literatura contemporânea. Acerca disso, Müller (2011, p.2) discorre que "questões menores, particulares, são agora as mais urgentes. É necessário focar nas necessidades e conflitos do 'eu' como peça separada do todo". O escritor, por sua vez, contrasta com esses diversos componentes, pois não consegue pensar em começar uma nova vida sem sua esposa Lucie. Ele é a figura da permanência; pela relação duradoura entre ele e sua esposa chegamos à complementaridade entre masculino e feminino, tão exploradas pelo simbolismo yin-yang, que carregam consigo, respectivamente, a noite e o dia, a Terra e o Céu (CHEVALIER; GHEERBRANT, 1982, p. 968). A figura de sua mulher traz à tona a dor do escritor: "havia uma dor só dela, só de Lucie, que nenhum fotógrafo ou escritor do mundo teria a competência para reproduzir" (LISBOA, 2016, p. 133). É nessa permanente simbiose - “o Yin e o Yang, embora representem dois contrários, jamais se opõem de modo absoluto", representando as relações espaço-temporais ao dividir "o tempo em períodos e o espaço em regiões" (CHEVALIER; GHEERBRANT, 1982, p. 969) - que a fragilidade do narrador é exposta.

O fotógrafo é a exibição da fluidez; é um ser desterrado na própria terra, sem laços que o prendam. É o andarilho descrito por Bauman (1996), aquele que está sempre em movimento, sem residência fixa. Sempre com "risco de se perder" (LISBOA, 2016, p.113), o narrador decide se aventurar em um novo ambiente com o qual não está familiarizado, em busca de se (re)encontrar. Implora a sua amiga editora para ir fotografar, a fim de apreender instantes que dele escapam e abrir os olhos para se deparar com algo muito diferente de si (LISBOA, 2016, p.115). Sua fluidez é tamanha que acaba tornando-se deslocado em relação a tudo ao seu redor, como pode ser percebido na visita à igreja, "quase transformada em museu, por fim reconsagrada ao culto bizantino" (LISBOA, 2016, p.125). A escolha da igreja não se deu por 
acaso: serviu para destacar o contraponto entre ele, viajante, ser em movimento, e a acácia, estática, um ponto fixo em meio a tanto deslocamento.

Lisboa também apresenta em seu conto um elemento simbólico de destaque: o gato. Segundo Chevalier e Gheerbrant (1982), o felino possui uma definição heterogênea, uma vez que pode representar o bem e o mal - principalmente se for preto -, a vida e a morte. No universo budista, o animal não é bem quisto, pois segundo lendas locais, o gato e a serpente foram os únicos animais que não choraram com a morte de Buda. No Camboja, mais precisamente no Kampuchea, é o símbolo responsável por trazer chuva num ritual que consiste em levá-lo, preso em uma gaiola, de casa em casa numa espécie de procissão, a fim de obter altos índices pluviométricos. No Egito antigo, o bichano era idolatrado, pois simbolizava força e agilidade disponíveis para o uso humano.

No texto de Lisboa, o gato preto do casal Gérard Baer e Lucie Naval possui um duplo sentido: "Um gato que Lucie havia salvado da morte por atropelamento e levado para casa anos antes" (LISBOA, 2016, p. 127). Esse trecho permite ao leitor pensar na dualidade representada pelo felino - ao mesmo tempo em que representa a vida, por ter sido salvo pela esposa do escritor, traz presságios de morte, pois acompanha o que estava para acontecer com seus donos. O misticismo do animal também pode ser observado no momento em que o gato encara o narrador. É ele a primeira personagem da trama que nota a confusão presente no protagonista, quando nem o próprio é capaz de compreender o que se passa consigo; sua simbologia assume, assim, papel de suma importância para o desenrolar da história.

A fotografia é outro elemento vital ao contexto simbólico do conto, visto que, no processo de construção literária, a foto estabelece uma importante analogia com o gênero. Cortázar (1974), nesse sentido, afirma que

o fotógrafo ou o contista sente a necessidade de escolher e limitar uma imagem ou um acontecimento que sejam significativos, que não só valham por si mesmos, mas também sejam capazes de atuar no espectador ou no leitor como uma espécie de abertura, de fermento que projete a inteligência e a sensibilidade em direção a algo que vai muito além do argumento visual ou literário contido na foto ou no conto. (CORTÁZAR, 1974, p.151; tradução nossa; grifos do autor)

Para o escritor argentino, a relação entre romance e cinema existe paralelamente à entre conto e fotografia. Aqueles se ligam porque possuem uma extensão maior para desenvolver o enredo; o romance contém o tempo a seu favor, o que faz com que o romancista possa oferecer um maior detalhamento ao longo de suas produções por meio do gênero. Já o contista, assim 
como o fotógrafo, não possui tal facilidade, uma vez que parte da captação de um momento em um tempo-espaço para, a partir daí, contar a sua história. $\mathrm{O}$ autor de contos trabalha a partir da limitação de páginas e, por isso, tem que prender o leitor desde o início. A presença do fotógrafo no conto torna-se simbolismo do próprio fazer literário, pois "o fotógrafo se permite observar, andar pelas ruas, apenas exercitando o olhar e captando o que vê através da câmera" (KNIJNIK, 2013, p.4). Além disso, ao se valer do ato de fotografar, o escritor tem algo para contar, pois, a partir de uma foto, "ele se volta para tecer as relações entre as personagens: é atento observador e também criador, dando vida à foto petrificada no tempo. A narração se clarifica entre a atenção e a imaginação. O escritor sai vitorioso: existe uma história para contar" (KNIJNIK, 2013, p.10).

Podemos observar que a presença da fotografia não se dá aleatoriamente, haja vista a semelhança no modo de trabalho do contista e do fotógrafo para a captação de um acontecimento cotidiano na tentativa de eternizá-lo. No conto de Lisboa não é diferente: o narrador-viajante busca, por meio da fotografia, a sua permanência no mundo, a fim de sanar a sua fragilidade existencial, como destaca no trecho a seguir: "sempre corri o risco de me perder. E de perder as coisas. Pior do que isso: de perder as pessoas. Deve ser por isso que fotografo. Para não perder tanto assim” (LISBOA, 2016, p.113-114).

Tal pensamento acompanha o protagonista durante todo o texto. Primeiro, começa tirando fotos de Carla, no apartamento dela alugado por ele durante sua estadia em Paris, com o objetivo de evitar "que a moça se desmanchasse no ar [...], ali mesmo, junto à janela, entre flores e frutas e uma garrafa de água mineral.” (LISBOA, 2016, p.121). Percebemos aqui o seu interesse na mulher, pois não queria perdê-la, e o ato da foto permite a ilusão de permanência. Posteriormente, o fotógrafo compara o ato de fotografar ao de caçar borboletas, porque ambas as ações buscam guardar uma beleza para sempre.

O colecionador mata o inseto com éter [...] porque a beleza dói demais e ele não consegue aguentar. [...] Espeta com alfinete, estica, escreve etiqueta de identificação e guarda numa caixa de madeira com naftalina. Eu poderia botar uma etiqueta para as fotos daquela moça, meu nome como coletor. (LISBOA, 2016, p.121-122).

Só há a certeza de que a personagem está em busca da eternidade quando nos diz: "Eternidade. O que buscavam os homens em suas igrejas e livros. Um instante e mais outro. Uma página, uma foto, uma pedra, e mais outra e mais outra" (LISBOA, 2016, p.126). Com esse trecho, somos levados aos estudos de Cortázar (1974), uma vez que o autor corrobora a ideia de captação de um momento específico para torná-lo eterno. Percebemos então que a 
fotografia tem papel fundamental na obra, pois norteia a relação entre o indivíduo e o tempoespaço, bem como entre o contista e seu fazer literário. Quanto a isso, o narrador afirma: "não devia ser natural aquilo de viajar pelo relógio do mundo. No dia seguinte eu acordei no futuro" (LISBOA, 2016, p.123-124). Mais uma vez, o deslocamento age em prol do desenraizamento e da reconstrução identitária.

\section{Conclusão}

Observamos que o tema do deslocamento moldou a forma de se fazer literatura na contemporaneidade, porque condiciona relatos e simbologias presentes entre o narradorviajante e o tempo-espaço. Podemos perceber tais efeitos do deslocamento, em especial por meio da vivência subjetiva das personagens enquanto seres em trânsito, visto que passam por experiências que as colocam na condição de desterrados, de andarilhos em terra estrangeira.

Por meio da análise de "O escritor, sua mulher e o gato", de Lisboa, observamos a preocupação da narrativa brasileira contemporânea com a problematização da noção de 'identidades em trânsito'. No conto, tudo passa pela visão do narrador, estrangeiro que explora o ambiente alheio pelo seu olhar deslocado, como um 'detetive do lugar', investigando aspectos que remontam sua identificação enquanto ser viajante. O processo de reconhecimento faz a conexão entre experiências novas e antigas, produzindo, ao mesmo tempo, intimidade e estranhamento. Isso fica evidente ao analisarmos o percurso traçado pelo narrador-personagem, que vai além de uma viagem Brasil-França. É a busca por pertencimento que norteia o trajeto do protagonista, e, com o auxílio da fotografia, ele consegue produzir imagens que possam leválo à compreensão de sua própria condição. Entendendo que o conto, como a fotografia, “pressupõe uma limitação prévia devido ao espaço reduzido que a câmera pode abranger e pelo modo com que o fotógrafo usa essa limitação" (PORTO, 2015, p.113), observamos que tal limitação é crucial à representação da impermanência e da fluidez pela literatura, a qual produz seres também limitados, fragmentados, in progress, em busca de si pelo tempo-espaço móbil.

É importante ressaltar que, no conto em questão, os simbolismos possuem um papel crucial ao desenvolvimento do enredo, uma vez que geram a extensão necessária à completude do texto e auxiliam na compreensão do mundo para além da representação literária. Elementos como o jogo de luzes e sombras, a dualidade yin-yang, a imagem do gato, assim como a do andarilho-viajante, somam-se ao valor simbólico da fotografia, constituindo uma narrativa que 
tem, em seu cerne, a construção do próprio conto, pois é a partir da captação de um momento que o escritor vai desenvolver toda uma história - ou melhor, vai produzir uma história dentro da outra.

A mobilidade presente no conto dialoga com o conceito de identidade cultural trazido por Hall e Du Gay (1996), os quais nos apresentam que, nos aglomerados urbanos, há cidadãos segregados dos demais, mas que também compartilham história e ancestralidade. Tal ideia nos permite compreender, por exemplo, a conexão entre o fotógrafo e Carla. Ambos possuem uma mágoa do passado: ele, o divórcio e a solidão; ela, a frustração de não realizar o sonho de ser atriz. Ambos buscam na cidade-luz, de um modo ou de outro, a redenção. Essa mistura de identidades, contrastes e dualidades representa a tendência da literatura brasileira contemporânea - e da narrativa curta especificamente - em explorar o individual. Como diz Müller (2011, p.2), “o conto é direcionado para esse sujeito egocêntrico, criado pela modernidade, e o analisa em um momento específico; como num momento de solidão, temos apenas aquelas características momentâneas para estimar o seu conteúdo”.

Portanto, observamos que a identidade, cada vez mais transitória, está inserida na subjetividade da narrativa contemporânea e na forma como esta absorve e representa as consequências de um mundo globalizado. Nesse sentido, Bhabha (1994, p. xv) ressalta que a globalização “deve sempre iniciar em casa"; é partir desta que a diferença e (não)pertencimento são sentidos e projetados. A produção literária de Adriana Lisboa é um claro exemplo de como o indivíduo é representado face aos reflexos da globalização, trazendo à tona personagens fluídas, errantes, desenraizadas de seus espaços de origem, que desfazem a relação dicotômica existente entre local e global. Pelos simbolismos de sua obra, experimentamos não apenas a (re)definição do conto contemporâneo enquanto gênero da mobilidade, mas também visualizamos deslocamentos transnacionais em diálogo com outros, os quais atravessam, pela subjetividade, as relações de alteridade.

\section{Referências}

BAUMAN, Zygmunt. From pilgrim to tourist: or a short history of identity. In: HALL, Stuart; DU GAY, Paul (Org.). Question sof cultural identity. Londres: Sage, 1996. cap. 2, p. 18-37.

BAUMAN, Zygmunt. Globalization: The Human Consequences. Cambridge: Polity, 2012. BAUMAN, Zygmunt. Identidade. Rio de Janeiro: Jorge Zahar, 2005. 
BHABHA, Homi. The location of culture. Londres; Nova York: Routledge, 1994.

CHEVALIER, Jean; GHEERBRANT, Alain. Dicionário de Símbolos. Rio de Janeiro: José Olympio, 1982.

CORTÁZAR, Julio. Alguns aspectos do conto. In: CORTÁZAR, Julio..Valise de cronopio. São Paulo: Perspectiva, 1974.

HALL, Stuart; DU GAY, Paul (Org.). Questions of cultural identity. Londres: Sage, 1996.

HALL, Stuart. A identidade cultural na pós-modernidade. 10.ed. Rio de Janeiro: DP\&A, 2005.

SCHØLLHAMMER, Karl Erik. Ficção brasileira contemporânea. Rio de Janeiro: Civilização Brasileira, 2009.

KNIJNIK, João. O fotógrafo visto pelo conto "As babas do diabo" de Júlio cortázar e pelo filme Blow-up de Michelangelo Antonioni: uma comparação. In: $9^{\circ}$ INTERPROGRAMAS DE MESTRADO FACULDADE CÁSPER LÍBERO, 2013, São Paulo. Anais [...]. São Paulo: Faculdade Cásper Líbero, 2013. Disponível em: https://casperlibero.edu.br/wpcontent/uploads/2014/04/Jo\%C3\%A3o-Knijnik.pdf. Acesso em: 30 abr. 2019

LISBOA, Adriana. O escritor, sua mulher e o gato. In: LISBOA, Adriana. O sucesso. Rio de Janeiro: Alfaguara, 2016. p.113-14).

MELO, Cimara Valim de. Transnacionalidades: Arte e cultura no Brasil contemporâneo. Porto Alegre: Metamorfose, 2017. 214 p.

MÜLLER, Natália Galdino. A importância da narrativa na estruturação temática do conto. In: SIMPÓSIO INTERNACIONAL LITERATURA, CRÍTICA, CULTURA V: LITERATURA E POLÍTICA, 2011, Juiz de Fora. Anais [...]. Juiz de Fora (MG): Darandina Revista eletrônica, 2011. Disponível em:

http://www.ufjf.br/darandina/files/2011/09/A_import\%C3\%A2ncia_da_narrativa_na_estrutur a\%C3\%A7\%C3\%A3o_tem\%C3\%A1tica_do_conto.pdf. Acesso em: 30 abr. 2019.

POE, Edgar Allan. Sobre la trama, el desenlace y elefecto. In: PACHECO, Carlos; LINARES, Luis Barrera (Org.). Del cuento y sus alrededores. Venezuela: Monte Avila Editores Latinoamericanos, 1997. p. 311-315.

PIGLIA, Ricardo. O Laboratório do escritor. São Paulo: Iluminuras, 1994.

PORTO, Luana Teixeira ; PORTO, Ana Paula Teixeira. Literatura contemporânea: limitações do gênero conto para leitura de textos de André Sant'anna. Revista Recorte, Belo Horizonte, 2018. Disponível em: http://periodicos.unincor.br/index.php/recorte/article/view/4952.

Acesso em: 28 abr. 2019.

PORTO, Luana Teixeira. O conto na visão crítica de Julio Cortázar: atenção à criação literária, lugar de destaque para o leitor. Revista Estação Literária, Londrina, PR, 2015. 
Disponível em: http://www.uel.br/pos/letras/EL/vagao/EL14-Art9.pdf. Acesso em: 28 abr. 2019.

SANTIAGO, Silviano. O entre-lugar do discurso latino-americano. In: SANTIAGO, Silviano. Uma literatura nos trópicos: ensaios sobre dependência cultural. 2.ed. Rio de Janeiro:

Rocco, 2000.

TEIXEIRA, Glauciane Reis. Do trânsito à fixação: reflexões sobre Berkely, de João Gilberto Noll. In: MELO, Cimara Valim de. Transnacionalidades: Arte e cultura no Brasil contemporâneo. Porto Alegre: Metamorfose, 2017. p. 67-90.

WATSON, James. Cultural Globalization. Encyclopedia Britannica, 2017. Disponível em: https://www.britannica.com/science/cultural-globalization. Acesso em: 15 fev. 2020.

RECEBIDO EM: 13/08/2019 APROVADO EM: 15/10/2019 